Check for updates

Cite this: RSC Adv., 2019, 9, 27060

Received 22nd July 2019

Accepted 14th August 2019

DOI: 10.1039/c9ra05664e

rsc.li/rsc-advances

\section{Gallic acid-functionalized graphene hydrogel as adsorbent for removal of chromium (III) and organic dye pollutants from tannery wastewater}

\author{
Gongyan Liu, (D) ab Ruiquan Yu, ${ }^{\text {ab }}$ Tianxiang Lan, ${ }^{\mathrm{b}}$ Zheng Liu, ${ }^{\mathrm{c}}$ Peng Zhang ${ }^{\mathrm{d}}$ \\ and Ruifeng Liang*d
}

The pollution caused by tannery wastewater containing high concentrations of trivalent chromium ions [Cr(III)] and organic dyes has severely restricted the sustainable development of the leather industry. To address this problem, a three-dimensional (3D) porous graphene-based hydrogel with good mechanical strength and large surface area was fabricated by self-assembly of graphene oxide (GO) sheets reduced and modified by gallic acid (GA) through $\pi-\pi$ interactions. As an adsorbent, this GA-functionalized graphene hydrogel (GA-GH) can effectively capture $\mathrm{Cr}(\mathrm{III})$ by coordination complexation between $\mathrm{Cr}(\mathrm{III})$ and deprotonated carboxylic groups of $\mathrm{GA}$ at $\mathrm{pH} \sim 4$.0. Moreover, GA-GH could be easily regenerated by desorption of adsorbed $\mathrm{Cr}(\mathrm{III})$ at $\mathrm{pH} 2.0$ and maintained its high adsorption capacity after multiple adsorption-desorption cycles, which was also helpful for reusing desorbed $\mathrm{Cr}(\mathrm{III})$ as tanning agent. In addition, compared with a graphene hydrogel (GH) without modification by GA, adsorption capacity of GA-GH for organic dye was significantly improved due to the enhanced $\pi-\pi$ interactions between the GA-GH and aromatic dyes.

\section{Introduction}

Leather or leather goods, such as footwear, clothing and bags with different colors are necessities in most people's daily lives. At present, over $90 \%$ of leather products are tanned using $\mathrm{Cr}$ (III) salts, due to their excellent hydrothermal stability, and physical and mechanical properties..$^{1-3}$ The chrome tanning mechanism is mainly based on coordination complexation between $\mathrm{Cr}$ (III) and deprotonated carboxyl groups of skin collagen under acidic $(\mathrm{pH} \sim 4.0)$ conditions, which results in chemical cross-linking of collagen fibers and conversion of rawhide to stable leather. ${ }^{4-6}$ However, in the conventional chrome tanning process, only approximately $70 \%$ of the total chrome agent is absorbed by the leather, leading to accumulation of $\mathrm{Cr}$ (III) in tannery wastewater to concentrations higher than $3000 \mathrm{ppm}^{7,8}$

\footnotetext{
${ }^{a}$ National Engineering Laboratory for Clean Technology of Leather Manufacture, Sichuan University, Chengdu 610065, China

${ }^{b}$ The Key Laboratory of Leather Chemistry and Engineering of Ministry of Education, Sichuan University, Chengdu 610065, China

'Jiangsu Province Special Equipment Safety Supervision and Inspection Institute, Wuxi 214717, China

${ }^{d}$ The State Key Laboratory of Hydraulic and Mountain River Engineering, Sichuan University, Chengdu 610065, China. E-mail: lrfcy@163.com

$\dagger$ Electronic supplementary information (ESI) available: The schematic transformation of GA under alkali conditions, illustration of the formation process of GA-GH, $\mathrm{N}_{2}$ adsorption-desorption isotherms of GA-GH, high-resolution of XPS of Cr peaks of GA-GH after adsorption for $\mathrm{Cr}$ (III). See DOI: $10.1039 / \mathrm{c} 9 \mathrm{ra} 05664 \mathrm{e}$
}

In China, according to relevant laws, this chromium-containing tannery wastewater is prohibited from being directly discharged to waterways until the concentration of $\mathrm{Cr}(\mathrm{III})$ is reduced to lower than 10 ppm. ${ }^{9}$ Unfortunately, current technologies for treating chromium wastewater, which normally utilize alkali chemicals to precipitate $\mathrm{Cr}$ (III) from wastewater to cause further pollution of sludge with $\mathrm{Cr}(\mathrm{OH})_{3}$, still lack efficiency and are less than satisfactory. $\mathrm{Cr}$ (III) in tannery sludge, on the one hand, is very difficult to collect and recycle, while on the other hand, it can be more easily oxidized into highly toxic hexavalent chromium $\mathrm{Cr}(\mathrm{vI})$ when the sludge is exposed to air, which will bring potential risk to human health. ${ }^{\mathbf{1 0 - 1 2}}$ Besides the $\mathrm{Cr}$ (III) pollutant in the chrome tanning process, various cationic and anionic organic dyes that can combine with skin collagen through electrostatic interactions are also widely used in the subsequent dyeing process during leather making. ${ }^{\mathbf{1 3 , 1 4}}$ In addition, most of these organic dyes are aromatic, resulting in tannery wastewater contaminated with aromatic pollutants, which are not only harmful to humans but also toxic to microorganisms. ${ }^{15-17}$ Indeed, tannery wastewater containing $\mathrm{Cr}(\mathrm{III})$ and organic dyes has become a serious environmental pollution, which has severely affected the sustainable development of the leather industry. ${ }^{18-20}$

For the removal of both $\mathrm{Cr}(\mathrm{III})$ ions and organic dyes from tannery wastewater, adsorption has proved to be an attractive disposal technique based on its low cost, simplicity of operation and recycling of the adsorbent. ${ }^{21-24}$ However, most traditional adsorbents, including polymeric resins ${ }^{25}$ activated carbon, ${ }^{26}$ 
silica, ${ }^{27}$ and metal oxides, ${ }^{28,29}$ usually suffer from either low adsorption capacity or low efficiency. Over the past decade, freestanding graphene hydrogel (GH), fabricated by self-assembly of reduced GO sheets through $\pi-\pi$ interactions, has attracted much attention as a super adsorbent for wastewater treatment, due to its unique properties, such as three-dimensional (3D) porous network structure, large surface area, low density, chemical stability and aromaticity. ${ }^{30-34}$ Up to now, the one-step hydrothermal method has been the most popular method to reduce GO sheets and subsequently obtain $3 \mathrm{D} \mathrm{GH} \cdot{ }^{35-37}$ However, such hydrothermal process is usually time-consuming $(\sim 12 \mathrm{~h})$ and requires very high temperature $\left(\sim 200^{\circ} \mathrm{C}\right)$, which limit the large-scale production of $\mathrm{GH}^{38-40}$ Recently, tremendous efforts have been devoted to fabricate $3 \mathrm{D}$ porous $\mathrm{GH}$ with the aid of chemical reduction under mild conditions, which is a process called in situ reducing-assembly. ${ }^{41}$ For instance, in the presence of a variety of reducing agent, GO sheets was reduced within 10 hours by heating at low-temperature below $100{ }^{\circ} \mathrm{C}$ and spontaneously self-assembled into a free-standing hydrogel through $\pi-\pi$ interactions. ${ }^{42}$ To meet the requirements of GH as effective adsorbent to remove heavy metal ions and organic pollutants from wastewater, reducing agents have also been carefully selected to play multi-functional roles as reductant, surface functionalization agent and provider of active sites for anchoring heavy metal ions and organic pollutants. ${ }^{43}$ For example, Duan's group developed a polydopamine (PDA) modified GH (PDA-GH) by using dopamine as both a reductant and surface functionalization agent, which had high adsorption capacity for heavy metals, synthetic dyes and aromatic pollutants, benefiting from the abundant and aromatic catechol groups of the PDA on the graphene sheets. ${ }^{44}$

Here, to effectively remove $\mathrm{Cr}(\mathrm{III})$ ions and aromatic dyes in tannery wastewater, natural gallic acid (GA) extracted from plants, which contains carboxyl groups and aromatic catechol groups, was selected to reduce and modify GO into selfassembled 3D porous GA-functionalized graphene hydrogel (GA-GH) as adsorbent (as shown in Scheme 1). Compared with pristine $\mathrm{GH}$, the GA-GH is supposed to improve the adsorption capacity for $\mathrm{Cr}(\mathrm{III})$ and aromatic dyes through complexation with the carboxyl group of GA, as well as enhanced $\pi-\pi$ interactions with the phenolic group of GA, respectively. The unique features of GA-GH including multi-functional groups, 3D porous structure and large surface area and free-standing make it a suitable and promising adsorbent candidate for removal of $\mathrm{Cr}(\mathrm{III})$ and aromatic dyes from tannery wastewater.

\section{Materials and method}

\subsection{Materials}

GO were prepared from natural graphite powder according to a modified Hummer's method. ${ }^{45}$ Gallic acid (GA, 99\%) was purchased from Aladdin Chemical Corporation (Shanghai, China). Chromium chloride hexahydrate $\left(\mathrm{CrCl}_{3} \cdot 6 \mathrm{H}_{2} \mathrm{O}, 99 \%\right)$, methylene blue (MB) and methyl red (MR) dyes were purchased from Shudu Chemical Co. Ltd. (Chengdu, China). Other chemical materials were purchased from Jinshan Chemical Reagents Corporation (Chengdu, China) and all were analytical reagents.

\subsection{Preparation of GA-GH}

The aqueous dispersions of $\mathrm{GO}$ at a concentration of $2 \mathrm{mg} \mathrm{mL}^{-1}$ and a $\mathrm{pH}$ value of 9.0 were first prepared, and then GA was added at a concentration equal to that of GO. GA-GH was obtained by heating the above mixture at $100{ }^{\circ} \mathrm{C}$ for 8 hours without any disturbance. For comparison purposes, hydrothermally-reduced $\mathrm{GH}$ was also prepared by hydrothermal treatment of $\mathrm{GO}$ aqueous solution $\left(2 \mathrm{mg} \mathrm{mL}^{-1}\right)$ at $180{ }^{\circ} \mathrm{C}$ for $12 \mathrm{~h}$. Then, the above as-prepared samples were dialyzed with deionized water for one week, followed by freeze-drying to obtain the dry GA-GH and GH.

\subsection{Adsorption and desorption properties of GA-GH for $\mathrm{Cr}(\mathrm{III})$}

Batch adsorption experiments were performed at room temperature to investigate the adsorption behaviors of $\mathrm{Cr}$ (III) on GA-GH or GH samples at $\mathrm{pH} 3.0$ or $\mathrm{pH} 3.8$. Typically, $10 \mathrm{mg}$ GA-GH or GH adsorbent was added into $100 \mathrm{~mL}$ aqueous solutions with different initial concentrations of $\mathrm{Cr}(\mathrm{III})$ at $\mathrm{pH} 3.0$ or $\mathrm{pH} 3.8$, shaking in

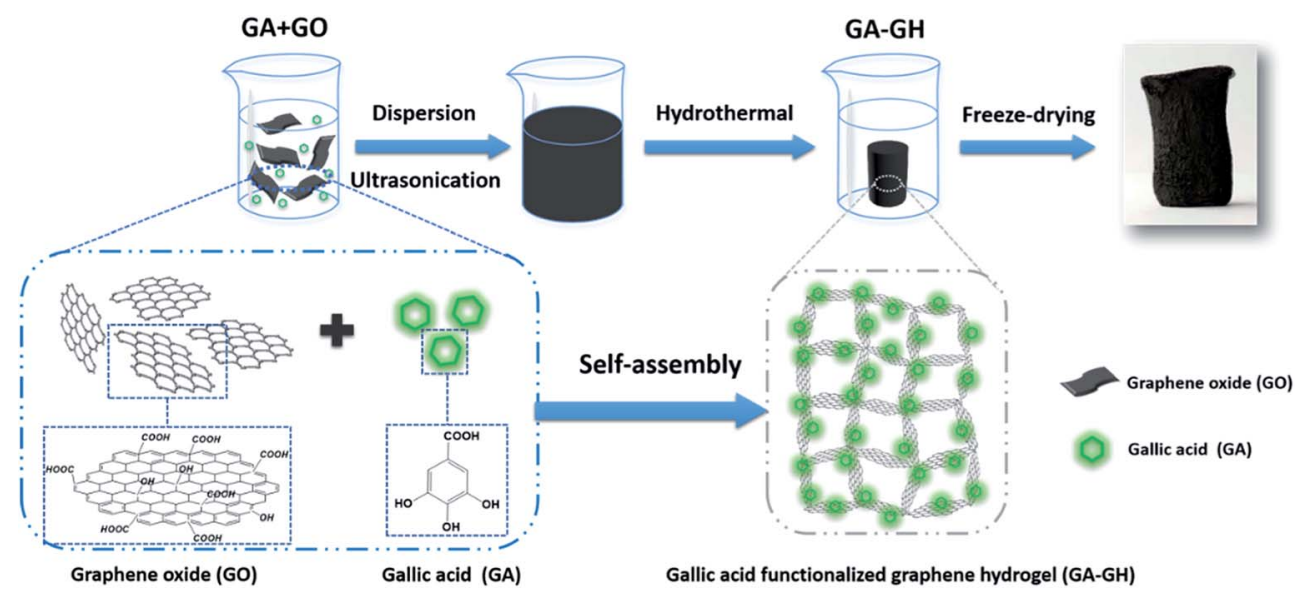

Scheme 1 Schematic illustration of the formation process of gallic acid functionalized graphene hydrogel (GA-GH). 
a rotary shaker for a period of time or $10 \mathrm{~h}$ to reach adsorption equilibrium. After adsorption, the GA-GH or GH was removed, and the solution was further centrifuged at $13000 \mathrm{rpm}$ for $20 \mathrm{~min}$. Inductively coupled plasma optical emission spectroscopy (ICPOES) was used to determine the residual Cr(III) concentration in the solution. The adsorption capacities of the adsorbents were calculated according to the equation: $q_{\mathrm{e}}=\left(C_{0}-C_{\mathrm{e}}\right) \mathrm{V} / \mathrm{m}$, where $C_{0}$ and $C_{\mathrm{e}}$ represent the initial and equilibrium concentrations $(\mathrm{mg}$ $\left.\mathrm{g}^{-1}\right)$, respectively; $V$ is the volume of the solutions $(\mathrm{mL}) ; m$ is the amount of adsorbent (mg). For desorption experiment, $\mathrm{HCl}$ was used as desorption agent to adjust the $\mathrm{pH}$ of the solution to $\mathrm{pH} 2.0$ for regenerating the adsorbents of GA-GH or GH after adsorption.

\subsection{Adsorption property of GA-GH for organic dye}

Two typical dyes used in traditional leather processing, namely $\mathrm{MB}$ and MR were chosen for the adsorption test. For dye adsorption, a $10 \mathrm{mg}$ amount of GA-GH or GH was added into a $20 \mathrm{~mL} \mathrm{MB}$ solution with $\mathrm{pH}$ of 7.0 at a concentration of $10 \mathrm{ppm}$ or a $20 \mathrm{~mL}$ MR solution with $\mathrm{pH}$ of 7.0 at a concentration of $20 \mathrm{ppm}$. The mixture was stirred continuously, and the sediment was collected and removed by centrifugation at $13000 \mathrm{rpm}$ for $20 \mathrm{~min}$. The concentration of residual dye solution was analyzed by ultraviolet-visible (UV-vis) spectroscopy at the maximum absorption wavelength to measure the absorbance. The concentration of each dye before and after adsorption was determined from the standard calibration curve.

\subsection{Characterization}

The morphology of the GA-GH and GH was examined by fieldemission scanning electron microscopy (FESEM) on a JSM7500F scanning electron microscope (JEOL Ltd., Tokyo, Japan). The chemical states of the element on the graphene aerogel surface were investigated by X-ray photoelectron spectroscopy, (XPS) using an XSAM 800 photoelectron spectroscope (Kratos Analytical, Ltd, Manchester, U.K.). X-ray diffraction (XRD) spectra were recorded on a D/max-2200/PC X-ray diffractometer (Rigaku Corporation, Tokyo, Japan) with $\mathrm{Cu} \mathrm{K} \alpha$ radiation. Thermogravimetric analysis (TGA) was performed using a TG209F1 Libra Thermogravimetric Analyzer (Netzsch NETZSCH Group, GmbH, Selb, Germany), from room temperature to $750{ }^{\circ} \mathrm{C}$ at a heating rate of $20{ }^{\circ} \mathrm{C} \mathrm{min}{ }^{-1}$ in air. The concentration of $\mathrm{Cr}(\mathrm{III})$ was determined by ICP-OES, using an Optima 2100DV spectrometer (PerkinElmer, Waltham, MA, USA). UV-vis diffuse reflectance spectra (UV-vis DRS) were recorded using a UV-3600 UV-vis-NIR spectrophotometer (Shimadzu, Kyoto, Japan) equipped with an integrating sphere and using $\mathrm{BaSO}_{4}$ as reference. The specific surface areas of GA-GH and $\mathrm{GH}$ were calculated by the Brunauer-Emmett-Teller (BET) method.

\section{Results and discussion}

\subsection{Preparation and characterization of GA-GH hydrogel}

GA, extracted from plant, is a kind of phenolic acid, showing reducibility under alkaline condition due to the transformation of its phenol group to a benzoquinone group (Fig. S1†). ${ }^{\mathbf{4 6 , 4 7}}$ As shown in Scheme 1, GA-GH was prepared by the one-step reduction-induced assembly of GO with the aid of GA, conducted at $100{ }^{\circ} \mathrm{C}$ for 8 hours at $\mathrm{pH}$ 9.0. However, as shown in Fig. 1A, the formation of the $\mathrm{GH}$ without GA using a similar hydrothermal reduction method required higher temperature $\left(180{ }^{\circ} \mathrm{C}\right.$ ) and longer time (12 hours). This is due to the partial reduction of GO sheets by GA during the formation of $\mathrm{GH}$, which weakened the hydrothermally synthesis process. At the same time, GA molecules were modified onto graphene sheets due to the catechol groups and strong affinity between aromatic rings. ${ }^{\mathbf{4 8 4 9}}$ After freeze-drying, the GA-GH exhibited a welldefined aerogel structure compared to that of the $\mathrm{GH}$, with obvious mechanical strength that can be capable of supporting a weight of $200 \mathrm{~g}$ (Fig. 1A and D). This might be due to the chemical reduction and modification of GO sheets by GA, and the increased $\pi-\pi$ interactions between graphene sheets, which lead to the formation of a more compact 3D porous architecture of the GA-GH. Therefore, the porous structure and morphology of GA-GH and GH we investigated by SEM. The SEM images of GA-GH shown in Fig. 1E and F clearly reveal a honeycomb-like structure with pores connecting the surface to the interior, which exhibited a more compact and ordered 3D porous network than that of the GH shown in Fig. 1B and C. These results indicated that the modification by GA enhanced the $\pi-\pi$ interactions between graphene sheets during the self-assembly process, leading to a well-defined and interconnected 3D porous structure (as shown in Scheme S1 $\dagger$ ).

To further investigate the modification of GA on graphene sheets, the chemical composition of GO, GH and GA-GH was determined by XPS analysis and compared. As can be seen, the XPS survey spectra of GO, GH and GA-GH samples shown in Fig. 2A, B and C, respectively, all displayed two sharp and strong peaks located at 285.2 and $532.1 \mathrm{eV}$, which were assigned to the $\mathrm{C} 1 \mathrm{~s}$ and $\mathrm{O} 1 \mathrm{~s}$, respectively. The element ratio of $\mathrm{C}$ and $\mathrm{O}$ for the $\mathrm{GH}$ sample that caculated from Fig. 2B is 4.48, which is much higher than $\mathrm{C} / \mathrm{O}$ ratio of 1.67 for GO sample caculated from Fig. 2A, suggesting the efficient reduction of the GO sheets during the hydrogel formation process. However, the $\mathrm{C} / \mathrm{O}$ ratio is 3.53 caculated from Fig. 2C for GA-GH sample, which is lower than that for GH sample, indicating the modification of GA on graphene sheets with carboxyl groups. To accurately confirm the compositional change of GO before and after reduction by the hydrothermal methods or GA, deconvolution of the $\mathrm{C} 1 \mathrm{~s}$ signal of three samples was performed. The $C$ 1s signal of the GO in Fig. 2D indicated the presence of heavily oxygenated carbon species, such as C-O (hydroxyl and epoxy, $\sim 286.5 \mathrm{eV}$ ), $\mathrm{C}=\mathrm{O}$ (carbonyl, $287.5 \mathrm{eV}$ ) and $\mathrm{O}-\mathrm{C}=\mathrm{O}$ (carboxyl, $\sim 288.6 \mathrm{eV}$ ). In contrast, after hydrothermal reduction, the intensity of the $\mathrm{C}-\mathrm{O}$ and $\mathrm{C}=\mathrm{O}$ peaks for the $\mathrm{GH}$ (Fig. 2E) dramatically decreased with the disappearance of the $\mathrm{O}-\mathrm{C}=\mathrm{O}$ peak, leading the peak associated with $\mathrm{C}=\mathrm{C}(\sim 284.7 \mathrm{eV})$ to become dominant. Instead, for the GA-GH sample that self-assembled by graphene oxide sheets reduced by $\mathrm{GA}$, the $\mathrm{O}-\mathrm{C}=\mathrm{O}$ peak that reappeared at $289.4 \mathrm{eV}$ (Fig. 2F) corresponded to the carboxyl groups of GA, confirming the functionalization of GA on the GH. 
A

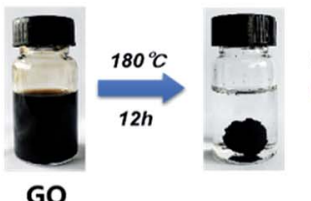

GO

D

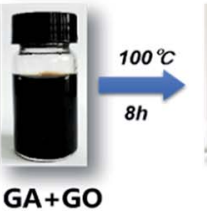

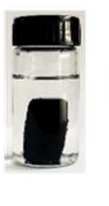

$\stackrel{\text { Freeze-drying }}{\longrightarrow}$
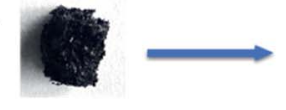

GH

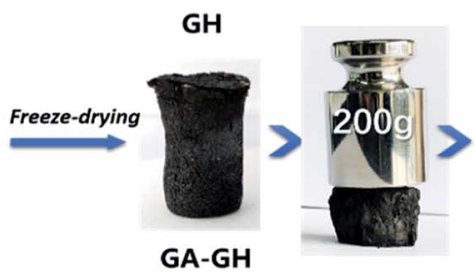

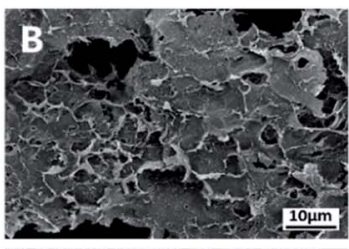
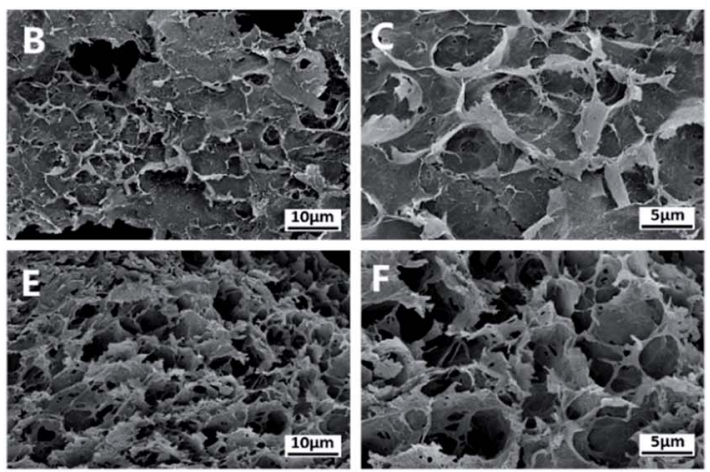

Fig. 1 Hydrothermally reduction of GO solutions with or without GA to form free-standing GH (A) and GA-GH (D). SEM images of GH (B and C) and GA-GH (E and F) with low and high magnifications.

The successful reduction of GO by GA was also verified by XRD analysis, using GO and GH samples as control. As shown in Fig. 3A, the XRD spectrum of GO displayed an intense peak at $2 \theta$ $=9.80^{\circ}$, implying an interlayer distance ( $d$-spacing) of $0.903 \mathrm{~nm}$ that can be attributed to the reflection of stacked GO sheets. After hydrothermal reduction of the GH sample, a new broad diffraction peak appeared at $26.30^{\circ}$ with a $d$-spacing of $0.338 \mathrm{~nm}$, which is almost the same as that of natural graphite $(0.336 \mathrm{~nm})$, indicating the sufficient removal of the oxygencontaining groups of GO and successful reduction of GO to graphene. For the GA-GH sample, a similar broad diffraction peak was found at $25.80^{\circ}$ and the interlayer spacing of the GAGH was calculated to be $0.345 \mathrm{~nm}$, which is slightly higher than that of GH. The above results demonstrated the presence of $\pi-\pi$ stacking interactions between reduced graphene oxide sheets in both hydrogel samples, which drive the overlapping and coalescing of flexible graphene sheets to form the 3D porous network structure that is observed by SEM (Fig. 1). ${ }^{37,44}$ In addition, GH and GA-GH also had similar specific surface areas, which were determined to be 282.1 and $298.6 \mathrm{~m}^{2} \mathrm{~g}^{-1}$, respectively, by the nitrogen adsorption-desorption test (Fig. S2†). However, in contrast to $\mathrm{GH}$, the slightly larger $d$-spacing of GA-
GH suggested the presence of GA with oxygenated functional groups (carboxyl) on graphene sheets, which is consistent with the results of the XPS analysis.

Thermal stability is an important indicator of the adsorption capacity of GH as an adsorbent. Therefore, the thermal stability of GA-GH was evaluated by TGA (Fig. 3B). The GO sample exhibited a drastic mass loss of $87 \%$ at $200^{\circ} \mathrm{C}$, which was due to the decomposition of labile oxygen containing groups on GO sheets and evaporation of absorbed water. Clearly, the massloss curves of the GH and GA-GH samples both showed less than $4 \mathrm{wt} \%$ weight loss at $200{ }^{\circ} \mathrm{C}$, indicating the improved thermal stability of the prepared GH. However, the weight loss of the GA-GH sample was higher than that of the GH sample when the temperature was above $250{ }^{\circ} \mathrm{C}$, which might be attributed to the decomposition of the functionalized GA on graphene sheets.

\subsection{The adsorption and desorption properties of GA-GH for $\mathrm{Cr}(\mathrm{III})$}

It is well-known that, in the conventional chrome tanning process, $\mathrm{Cr}(\mathrm{III})$ usually form $\mathrm{Cr}(\mathrm{OH})_{3}$ precipitates in aqueous solution at $\mathrm{pH}$ above 4.0 , but can form strong coordination
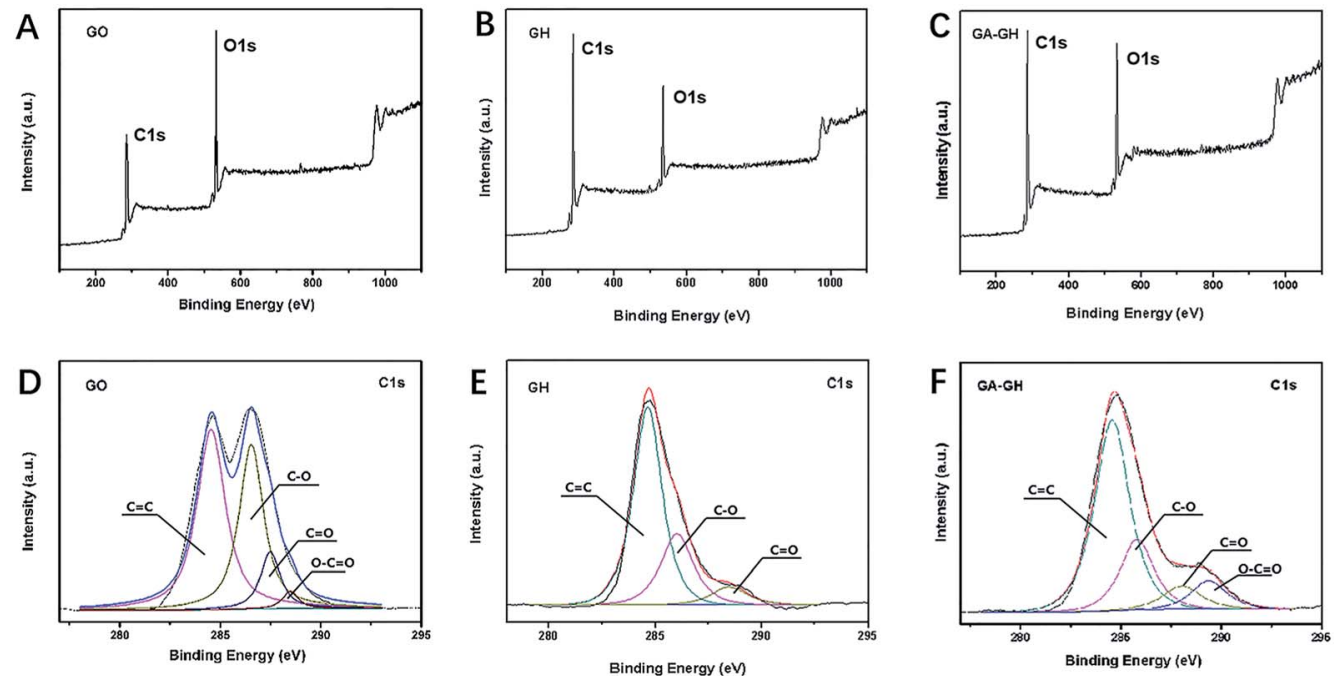

Fig. 2 XPS survey spectra of GO (A), GH (B) and GA-GH (C) samples. High-resolution XPS of C 1s peaks for GO (D), GH (E) and GA-GH (F) samples. 

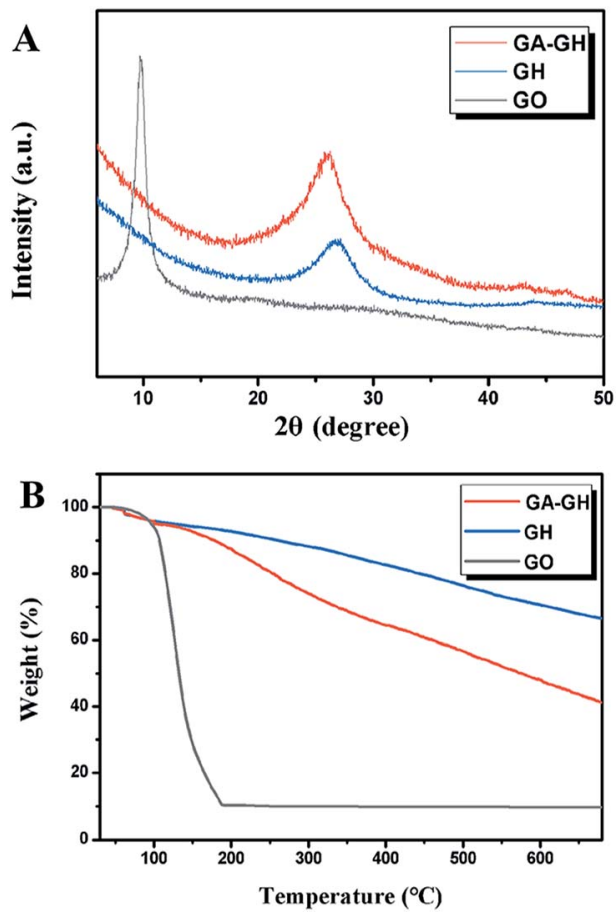

Fig. 3 XRD patterns (A) and TGA curves (B) of GO, GH and GA-GH samples.

complex bonds with deprotonated carboxyl groups $\left(-\mathrm{COO}^{-}\right)$at around $\mathrm{pH} 4.0{ }^{4}$ However, below $\mathrm{pH} \sim 3.0$, most of the carboxyl groups are protonated and have very weak interaction with $\mathrm{Cr}(\mathrm{III})$ ions. Thus, the $\mathrm{pH}$ value of the solution becomes a critical factor that may affect the adsorption capacity of the GA-GH. In this study, due to the modification of GA with carboxyl groups, it was anticipated that the GA-GH will have a more enhanced adsorption capacity than that of the $\mathrm{GH}$, and the adsorption performance of GA-GH will be better at the $\mathrm{pH}$ value around 4.0 than that at $\mathrm{pH}$ 3.0. Therefore, $\mathrm{pH}$ values of 3.8 and 3.0 were selected to evaluate the effect of the $\mathrm{pH}$ on the adsorption of $\mathrm{Cr}$ (III) onto GA-GH and GH, respectively. As shown in Fig. 4, the adsorption capacity of $\mathrm{GH}$ and GA-GH at $\mathrm{pH} 3.8$ and $\mathrm{pH} 3.0$, respectively, evaluated by equilibrium adsorption isotherm, both gradually increased with increasing concentration of $\mathrm{Cr}($ III), eventually reaching saturation states, with adsorption data all fitted into the Langmuir and Freundlich isotherm models, respectively. Moreover, the adsorption data were found to be better fitted with the Langmuir isotherm model than that by the Freundlich model, indicating that the adsorption of $\mathrm{Cr}(\mathrm{III})$ took place at the functional groups or binding sites on the surface of the adsorbent in a monolayer manner. From the fitting results, the maximum adsorption capacity of $\mathrm{Cr}$ (III) onto GH was 111.9 and $92.5 \mathrm{mg} \mathrm{g}^{-1}$ at $\mathrm{pH} 3.8$ and 3.0, respectively (Fig. 4A). For the GA-GH sample with equal adsorbent weight to that of $\mathrm{GH}$, the maximum adsorption capacity of $\mathrm{Cr}$ (III) was 305.4 and $152.2 \mathrm{mg} \mathrm{g}^{-1}$ at $\mathrm{pH} 3.8$ and 3.0, respectively (Fig. 4B). Evidently, the adsorption capacity of GA-GH for Cr(III) ions was much higher than that of GH, especially at $\mathrm{pH}$ 3.8. These results demonstrated the effective coordination complexation between
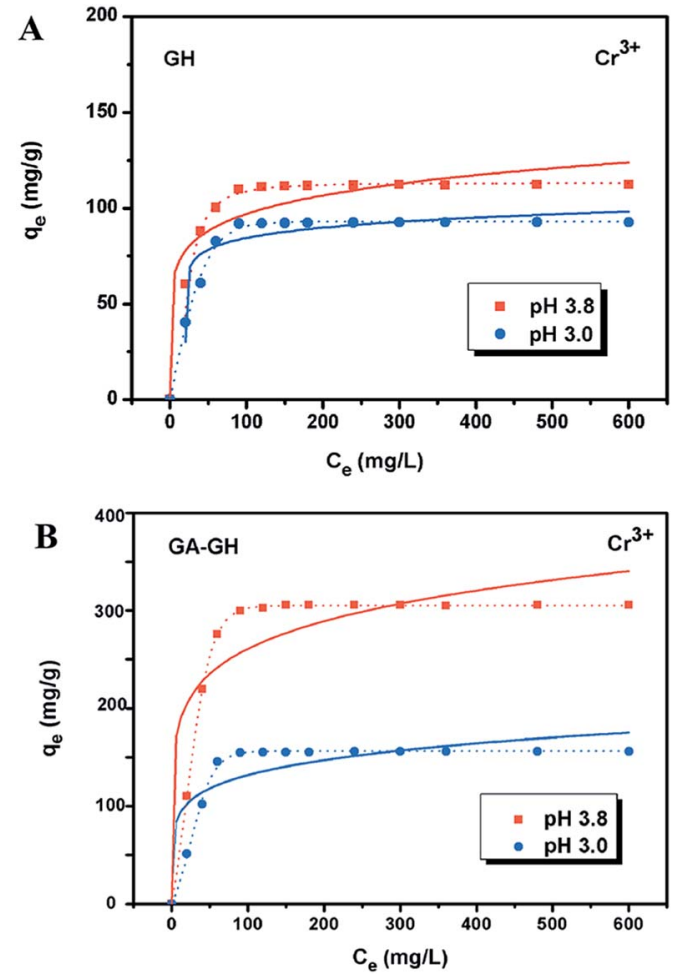

Fig. 4 Adsorption behaviors of $\mathrm{Cr}(\mathrm{III})$ on $\mathrm{GH}(\mathrm{A})$ and $\mathrm{GA}-\mathrm{GH}(\mathrm{B})$ at $\mathrm{pH}$ 3.0 and 3.8, respectively. Adsorption isotherm plots and curves were fitted by Langmuir (dot line) and Freundlich (solid line) models, with the equations given as $q_{\mathrm{e}}=q_{\max } K_{\mathrm{L}} C_{\mathrm{e}} /\left(1+K_{\mathrm{L}} C_{\mathrm{e}}\right)$ and $q_{\mathrm{e}}=K_{\mathrm{F}} C_{\mathrm{e}}{ }^{1 / n}$, respectively, where $q_{\mathrm{e}}$ is the amount $\left(\mathrm{mg} \mathrm{g}^{-1}\right)$ of $\mathrm{Cr}^{3+}$ ions adsorbed at equilibrium, $C_{e}$ is the equilibrium concentration $\left(\mathrm{mg} \mathrm{L}^{-1}\right)$ of $\mathrm{Cr}^{3+}$ ions, $K_{\mathrm{L}}$ and $q_{\max }$ (maximum adsorption capacity) are the Langmuir constants of adsorption, and $K_{\mathrm{F}}$ and $n$ are the Freundlich constants of adsorption.

$\mathrm{Cr}$ (III) and deprotonated carboxylic groups of GA modified on graphene sheets at $\mathrm{pH}$ value close to 4.0 during the adsorption process (illustrated in Scheme 2). In contrast, the adsorption capacity of the GA-GH for $\mathrm{Cr}(\mathrm{III})$ significantly decreased at $\mathrm{pH}$ 3.0, which showed the weaker binding affinity of protonated carboxylic groups to $\mathrm{Cr}(\mathrm{III})$.

The adsorption kinetics of $\mathrm{Cr}(\mathrm{III})$ by GH or GA-GH was also measured by using a metal ion concentration of $100 \mathrm{mg} \mathrm{L}^{-1}$ at $\mathrm{pH} 3.0$ and $\mathrm{pH} 3.8$, respectively. At different time intervals up to $10 \mathrm{~h}$, the samples were collected to calculate the adsorption capacity of $\mathrm{Cr}(\mathrm{III})$. As shown in Fig. 5, the adsorption amount of $\mathrm{Cr}$ (III) for $\mathrm{GH}$ or GA-GH at $\mathrm{pH} 3.0$ or 3.8 both increased dramatically within the initial $100 \mathrm{~min}$, and gradually reached equilibrium in $240 \mathrm{~min}$. At the same $\mathrm{pH}$ value, the adsorption rate of $\mathrm{Cr}$ (III) for GA-GH was much faster than that for GH. As anticipated, the adsorption rate of $\mathrm{Cr}(\mathrm{III})$ for $\mathrm{GA}-\mathrm{GH}$ at $\mathrm{pH} 3.8$ was faster and reached equilibrium within $60 \mathrm{~min}$. These results further indicated that the adsorption mechanism of $\mathrm{Cr}(\mathrm{III})$ onto GA-GH was mainly based on the complexation between $\mathrm{Cr}(\mathrm{III})$ and functionalized GA at around $\mathrm{pH}$ 4.0. In addition, it is clear that the pseudo-second-order kinetic model shown in Fig. 5B, which usually means that chemisorption is the rate-determining step, ${ }^{4}$ provided a better correlation in 


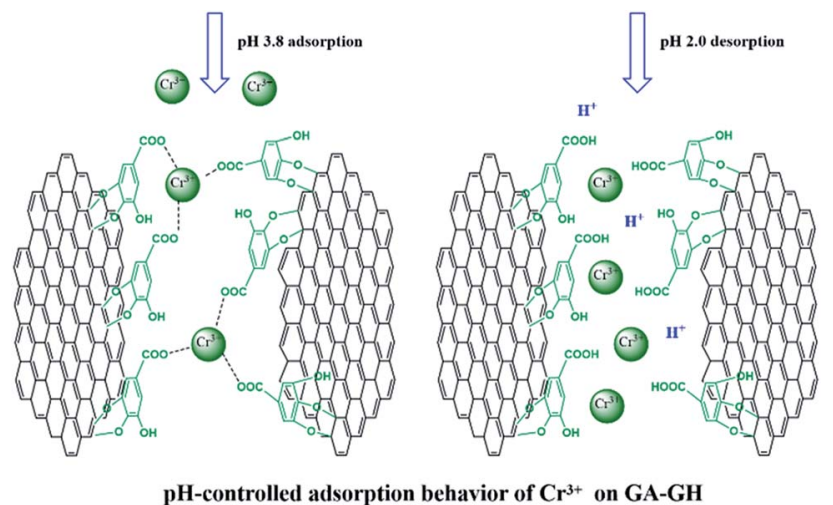

Scheme $2 \mathrm{pH}$-controlled adsorption and desorption behavior of $\mathrm{Cr}(\mathrm{III})$ ions on $\mathrm{GA}-\mathrm{GH}$.
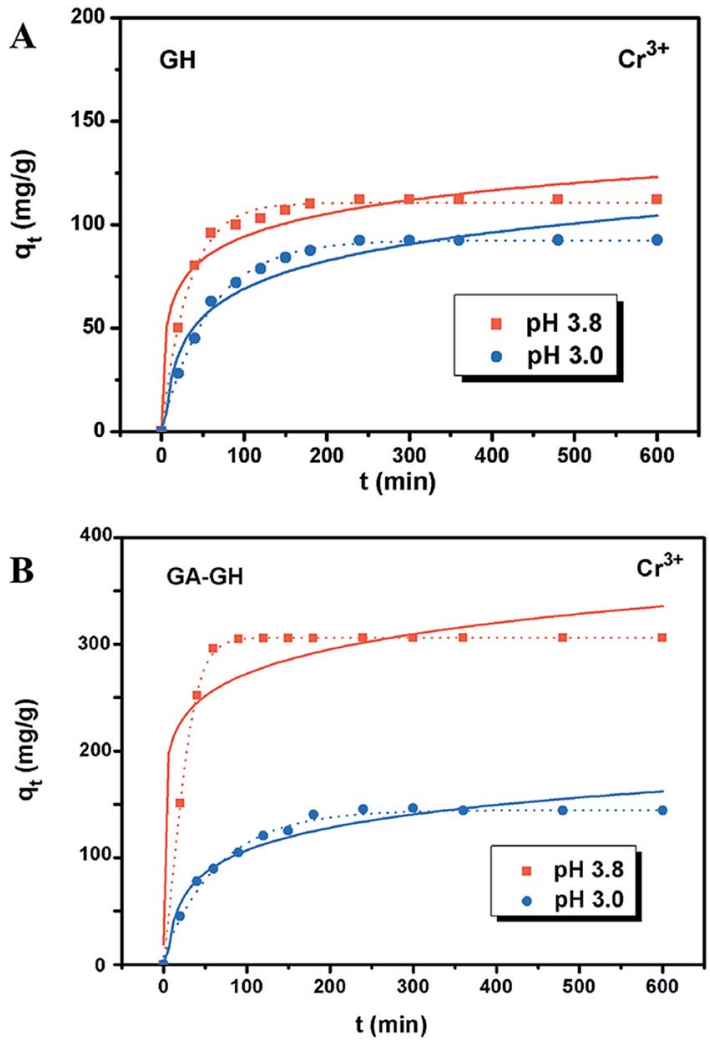

Fig. 5 Adsorption kinetic plots and curving fitting by pseudo-firstorder (solid line) and pseudo-second-order (dot line) kinetic models of $\mathrm{Cr}(\mathrm{III})$ on $\mathrm{GH}(\mathrm{A})$ and $\mathrm{GA}-\mathrm{GH}$ (B). The pseudo first order and pseudo second order kinetic models were according to the equations of $\ln \left(q_{\mathrm{e}}\right.$ $\left.-q_{t}\right)=\ln \left(q_{\mathrm{e}}\right)-k_{1} t$ and $t / q_{t}=1 / k_{2} q_{\mathrm{e}}^{2}+t / q_{\mathrm{e}}$, respectively, where $q_{\mathrm{e}}$ and $q_{t}$ are the capacities $\left(\mathrm{mg} \mathrm{g}^{-1}\right.$ ) of metal ions adsorbed at equilibrium and time $t(\mathrm{~min}), k_{1}$ is the rate constant of pseudo first order model $\left(\mathrm{min}^{-1}\right)$, and $k_{2}$ is the rate constant of the pseudo second order model of adsorption $\left(\mathrm{g} \mathrm{mg}^{-1} \mathrm{~min}^{-1}\right.$ ).

contrast to the pseudo-first-order model for the adsorption of $\mathrm{Cr}$ (III) onto GA-GH. This result also confirmed the existence of chemical complexation between GA-GH and $\mathrm{Cr}(\mathrm{III})$ during the adsorption process.
Since coordination complexation between $\mathrm{Cr}(\mathrm{III})$ and carboxyl groups is very weak at $\mathrm{pH}$ values below 3.0, the desorption of $\mathrm{Cr}(\mathrm{III})$ from GA-GH can be achieved under strong acidic condition. In our study, an $\mathrm{HCl}$ solution $(0.1 \mathrm{M})$ was selected as the desorption agent to recover $\mathrm{Cr}$ (III) from GA-GH and $\mathrm{GH}$ at $\mathrm{pH}$ 2.0. As expected, the results shown in Fig. 6A reveal that the desorption rate of $\mathrm{Cr}(\mathrm{III})$ from GA-GH was higher than that from GH, due to the protonation of GA (Scheme 2). After 20 min, nearly $97 \%$ of the adsorbed $\mathrm{Cr}$ (III) was desorbed from the GA-GH. In comparison, at least 30 min was needed to desorb $89 \%$ of adsorbed $\mathrm{Cr}(\mathrm{III})$ from GH. These findings indicated the excellent desorption efficiency for the GA-GH. Furthermore, the regenerated GA-GH steadily maintained its adsorption capacity even after 10 repeated adsorption and desorption cycles, which was also much higher than that of GH adsorbents (Fig. 6B). The chemical state of adsorbed chromium was also investigated by XPS. As shown in Fig. S3, $†$ the high resolution $\mathrm{Cr} 2 \mathrm{p}$ spectrum can be fitted into two peaks, which located at $578.8 \mathrm{eV}$ and $588.3 \mathrm{eV}$, respectively, which confirmed the trivalent chemical state of the adsorbed chromium and demonstrated $\mathrm{Cr}(\mathrm{III})$ was not oxidized into $\mathrm{Cr}(\mathrm{VI})$ during the adsorption process. The result suggested that the desorbed $\mathrm{Cr}(\mathrm{III})$ from GA-GH is potentially to be reused for tanning leather, which will be beneficial to the leather industry. Therefore, based on these results, the GA-GH can be applied as an
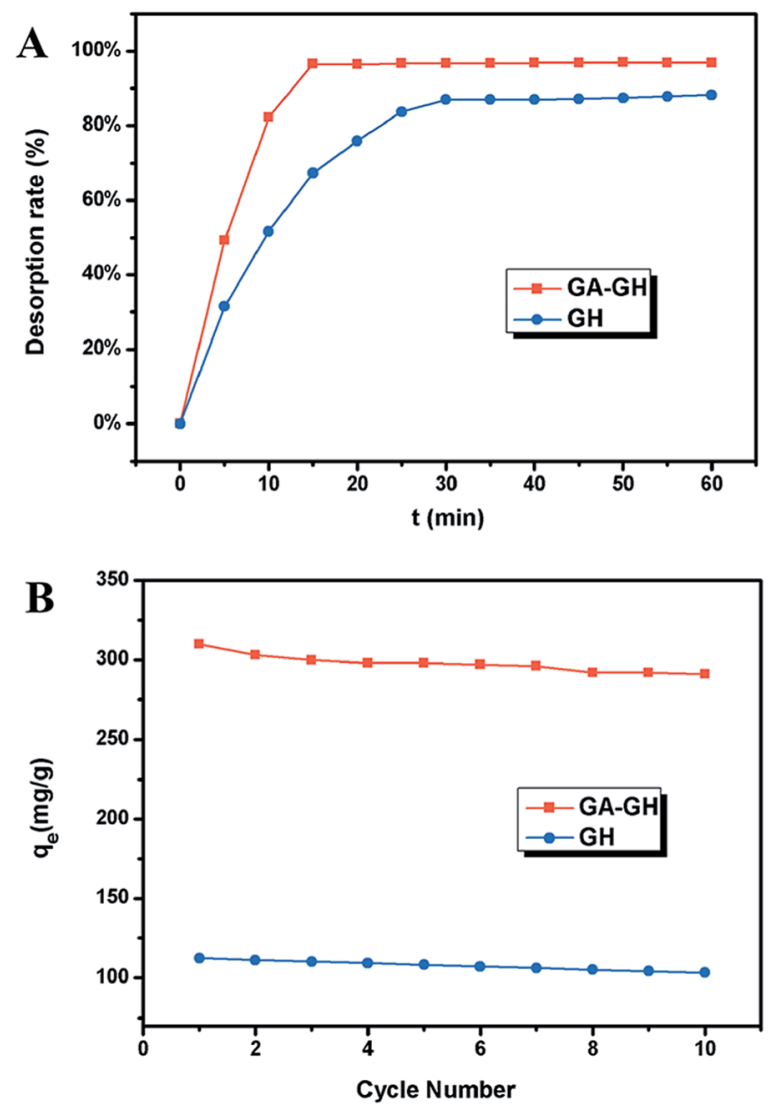

Fig. 6 (A) The desorption rate of $\mathrm{Cr}(\mathrm{III})$ from $\mathrm{GA}-\mathrm{GH}$ and $\mathrm{GH}$ at $\mathrm{pH}$ 2.0; (B) adsorption capacities of $\mathrm{GA}-\mathrm{GH}$ and $\mathrm{GH}$ as a function of repeated adsorption-desorption cycles for the removal of $\mathrm{Cr}(\mathrm{III})$. 
effective adsorbent for the removal of $\mathrm{Cr}(\mathrm{III})$ from tannery effluent.

\subsection{The adsorption properties of GA-GH for organic dye}

In this study, MB and MR were selected as models of cationic organic and anionic dyes, respectively, as they are commonly used in the dying process of leather making and are also the main source of organic pollutants in tannery effluent. As shown in Fig. 7A and B, the decolorization of the MB solution $(20 \mathrm{~mL}$, $10 \mathrm{ppm})$ and MR solution (20 mL, $20 \mathrm{ppm})$ in the presence of $10 \mathrm{mg}$ GA-GH after $2 \mathrm{~h}$ was conspicuous, indicating the effective organic dye adsorption capacity of GA-GH. Fig. 7A and B also revealed that the characteristic UV-vis absorption peaks of $\mathrm{MB}$ at $664 \mathrm{~nm}$ and of MR at $520 \mathrm{~nm}$ decreased with the adsorption time. After 2 hours, almost $98 \%$ of MB and $100 \%$ of MR could be captured by the GA-GH adsorbent at room temperature. The excellent adsorption capacity of GA-GH for MB and MR can possibly be attributed to $\pi-\pi$ interactions between the GA-GH and the aromatic organic dyes, as they drive the adsorbed organic dyes into the $3 \mathrm{D}$ porous hydrogel. To confirm this hypothesis, the adsorption kinetics of the aromatic MB or MR dye on GA-GH was further studied in comparison with that on $\mathrm{GH}$. Based on the results presented in Fig. 7E and F, the equilibrated adsorption capacity of MB and MR on GA-GH were calculated to be 395 and $376 \mathrm{mg} \mathrm{g}^{-1}$ at $2 \mathrm{~h}$, respectively, while for $\mathrm{GH}$, the equilibrated adsorption capacity of MB and MR was 305 and $287 \mathrm{mg} \mathrm{g}^{-1}$, respectively. The results clearly
A<smiles>CN(C)c1ccc2nc3ccc(=[N+](C)C)cc-3sc2c1</smiles>

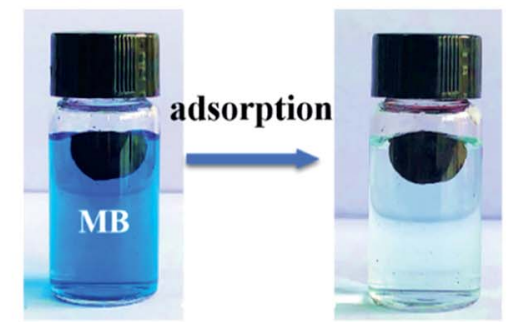

\section{C}
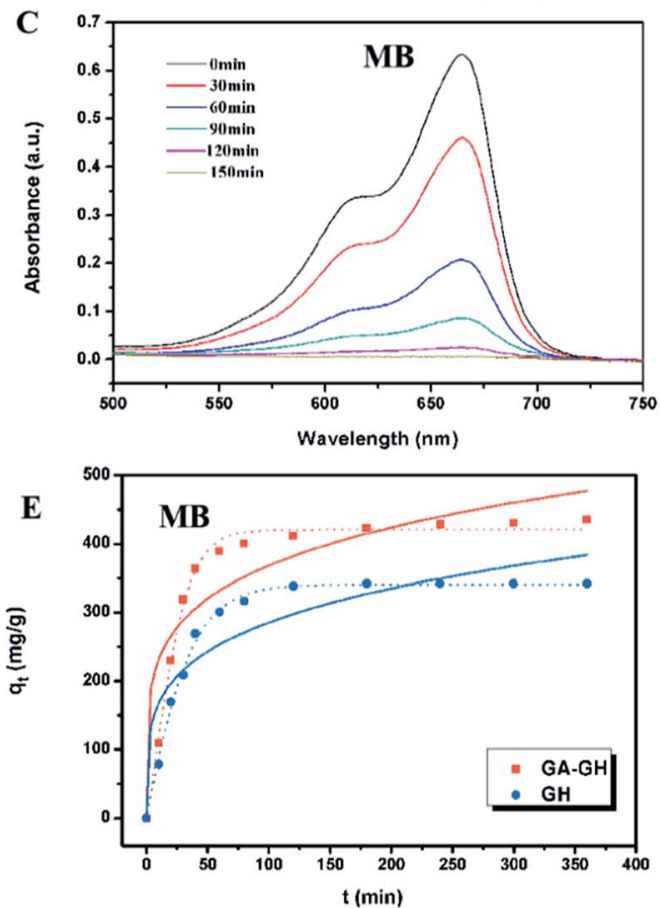

B
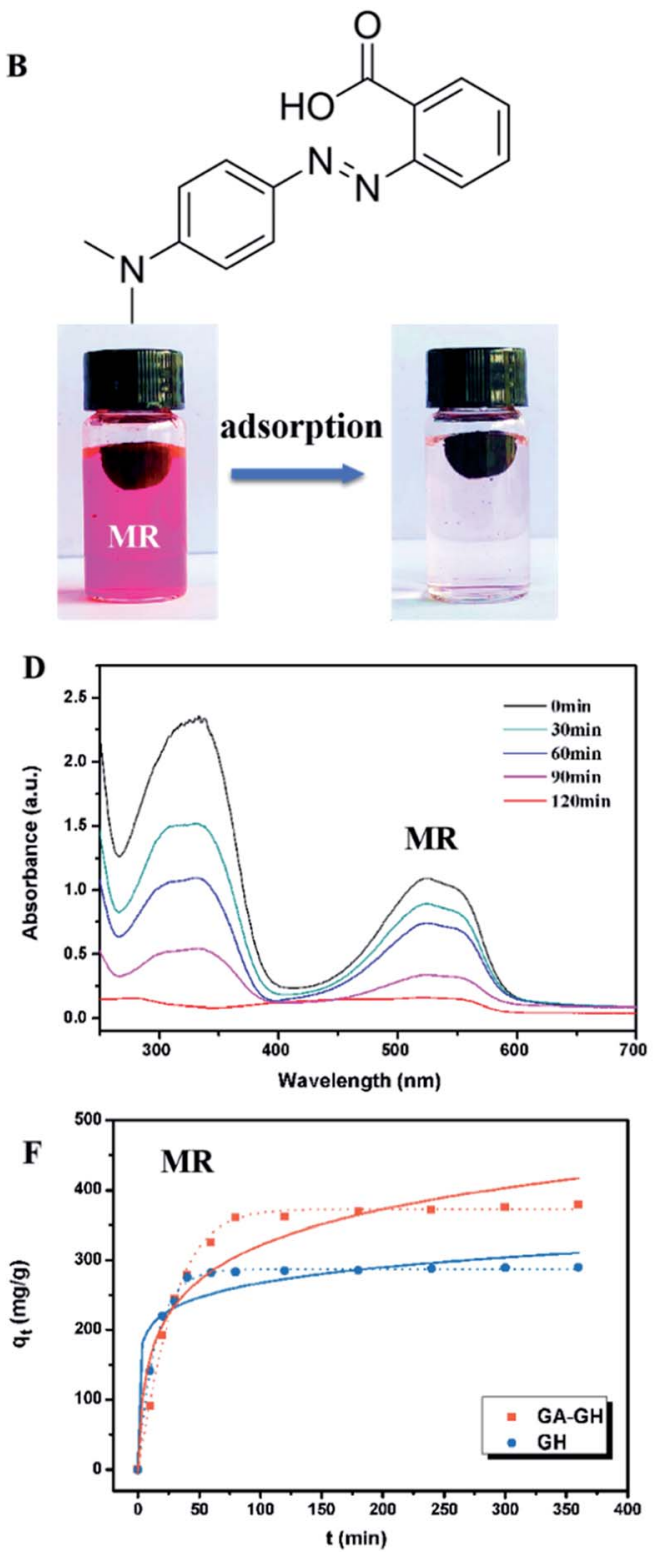

Fig. 7 (A and B) The chemical structure and color fading of MB and MR solution after adsorption by GA-GH; (C and D) the change of UV-vis absorption spectra of original MB (10 ppm) and MR (20 ppm) in the presence of GA-GH; (E and F) adsorption kinetic plots and curving fitting by pseudo-first-order (solid line) and pseudo-second-order (dot line) kinetic models of MB and MR on GH and GA-GH, respectively. 
demonstrated that the adsorption capacity of GA-GH for MB or MR was higher than that of GH, which confirm that the functionalized GA with a benzene ring enhanced the $\pi-\pi$ conjugation between the GA-GH and the aromatic MB or MR dye. Therefore, the GA-GH can also be applied as a suitable absorbent for the removal of aromatic pollutants from tannery effluent.

\section{Conclusions}

In order to effectively remove $\mathrm{Cr}(\mathrm{III})$ and organic dye from tannery wastewater, a GA-GH adsorbent with 3D porous architectures was successfully fabricated using a facile in situ reducing-assembly approach. Due to the carboxyl groups of GA, the GA-GH was able to effectively capture $\mathrm{Cr}$ (III) ions through coordination complexation at $\mathrm{pH}$ value close to 4.0 , leading to a much higher adsorption capacity of $\mathrm{Cr}$ (III) than that of the $\mathrm{GH}$. Importantly, GA-GH was easily regenerated at $\mathrm{pH} 2.0$ with $\mathrm{HCl}$ and retained its high adsorption capacity after multiple adsorption-desorption cycles. Moreover, the modified GA on graphene sheets with benzene group was also able to improve the adsorption capacity of organic dyes, which was attributed to the enhanced $\pi-\pi$ interactions between GA-GH and aromatic dyes. Taken together, the GA-GH is a promising adsorbent for treating tannery effluent.

\section{Conflicts of interest}

There are no conflicts declare.

\section{Acknowledgements}

This work was supported by Opening Project of Key Laboratory of Leather Chemistry and Engineering of Ministry of Education, Sichuan University (20826041C4159), Opening Project of State Key Laboratory of Hydraulics and Mountain River Engineering, Sichuan University and "the Fundamental Research Funds" for the Central Universities.

\section{Notes and references}

1 A. J. Bailey, N. D. Light and E. D. T. Atkins, Nature, 1980, 288, 408-410.

2 A. D. Covington, Chem. Soc. Rev., 1997, 26, 111-126.

3 K. Li, R. Yu, R. Zhu, R. Liang, G. Liu and B. Peng, ACS Sustainable Chem. Eng., 2019, 7, 8660-8669.

4 Y. Ding, D. Guo, J. Cheng, H. Zhang and M. Sui, Struct. Chem., 2016, 27, 1255-1263.

5 T. Lan, R. An, Z. Liu, K. Li, J. Xiang and G. Liu, J. Colloid Interface Sci., 2018, 532, 331-342.

6 Y. Zhang, B. W. Mansel, R. Naffa, S. Cheong, Y. Yao, G. Holmes, H. L. Chen and S. Prabakar, ACS Sustainable Chem. Eng., 2018, 6, 7096-7104.

7 J. Lu, J. Ma, D. Gao, B. Lyu and J. Zhang, J. Cleaner Prod., 2016, 139, 788-795.

8 S. Cao, K. Wang, S. Zhou, Y. Wang, B. Liu, B. Chen and Y. Li, ACS Sustainable Chem. Eng., 2018, 6, 3957-3963.
9 J. Zhang, D. L. Mauzerall, T. Zhu, S. Liang, M. Ezzati and J. V. Remais, Lancet, 2010, 375, 1110-1119.

10 H. Gu, S. B. Rapole, J. Sharma, Y. Huang, D. Cao, H. A. Colorado, Z. Luo, N. Haldolaarachchige, P. David, B. Walters, S. Wei and Z. Guo, RSC Adv., 2012, 2, 1100711018.

11 S. P. Goutam, G. Saxena, V. Singh, A. K. Yadav, R. N. Bharagava and K. B. Thapa, Chem. Eng. J., 2018, 336, 386-396.

12 L. Zhang, F. Fu and B. Tang, Chem. Eng. J., 2019, 356, 151160.

13 S. Ramalingam and R. R. Jonnalagadda, ACS Sustainable Chem. Eng., 2017, 5, 5537-5549.

14 S. Ramalingam, K. J. Sreeram, J. R. Rao and B. U. Nair, ACS Sustainable Chem. Eng., 2016, 4, 2706-2714.

15 T. Abou Elmaaty, J. Ma, F. El-Taweel, E. Abd El-Aziz and S. Okubayashi, Ind. Eng. Chem. Res., 2014, 53, 15566-15570.

16 J. Kanagaraj and R. C. Panda, Ind. Eng. Chem. Res., 2011, 50, 12400-12408.

17 S. S. Sun, T. Xing and R. C. Tang, Ind. Eng. Chem. Res., 2013, 52, 8953-8961.

18 Y. Gao and J. Xia, Environ. Sci. Technol., 2011, 45, 8605-8606. 19 G. Liu, K. Li, Q. Luo, H. Wang and Z. Zhang, J. Colloid Interface Sci., 2017, 490, 642-651.

20 J. Xiang, L. Ma, H. Su, J. Xiong, K. Li, Q. Xia and G. Liu, Appl. Surf. Sci., 2018, 458, 978-987.

21 H. S. Shang, Y. J. Lu, F. Zhao, C. Chao, B. Zhang and H. S. Zhang, RSC Adv., 2015, 5, 75728-75734.

22 P. L. Yap, S. Kabiri, D. N. H. Tran and D. Losic, ACS Appl. Mater. Interfaces, 2019, 11, 6350-6362.

23 A. J. Capezza, W. R. Newson, R. T. Olsson, M. S. Hedenqvist and E. Johansson, ACS Sustainable Chem. Eng., 2019, 7, 45324547.

24 L. Wen, K. Li, J. Liu, Y. Huang, F. Bu, B. Zhao and Y. Xu, RSC Adv., 2017, 7, 7688-7693.

25 Y. Fang, D. Lin and S. Yao, J. Chem. Eng. Data, 2018, 63, 44184424.

26 J. M. Ambrosy, C. Pasel, M. Luckas, M. Bittig and D. Bathen, Ind. Eng. Chem. Res., 2019, 58, 4208-4221.

27 Y. Zhao, Y. Zhu, T. Zhu, G. Lin, J. Huo, D. Lv, H. Wang and Y. Sun, Ind. Eng. Chem. Res., 2019, 58, 156-164.

28 X. Guan, J. Chang, Y. Chen and H. Fan, RSC Adv., 2015, 5, 50126.

29 R. K. Upadhyay, N. Soin and S. S. Roy, RSC Adv., 2014, 4, 3823-3851.

30 Y. Zhao, T. Sun, W. Liao, Y. Wang, J. Yu, M. Zhang, Z. Yu, B. Yang, D. Gui, C. Zhu and J. Xu, ACS Appl. Mater. Interfaces, 2019, 11, 22794-22800.

31 L. Zhu, R. Liu, Z. Fang, P. O. Agboola, N. F. Al-Khalli, I. Shakir and Y. Xu, ACS Appl. Mater. Interfaces, 2019, 11, 2218-2224.

32 Y. Wang, P. Zhang, C. F. Liu and C. Z. Huang, RSC Adv., 2013, 3, 9240-9246.

33 X. Zhang, T. Zhang, Z. Wang, Z. Ren, S. Yan, Y. Duan and J. Zhang, ACS Appl. Mater. Interfaces, 2019, 11, 1303-1310.

34 S. Li, J. Zheng, J. Yan, Z. Wu, Q. Zhou and L. Tan, ACS Appl. Mater. Interfaces, 2018, 10, 42573-42582.

35 H. Sun, L. Cao and L. Lu, Nano Res., 2011, 4, 550-562. 
36 C. Li and G. Shi, Nanoscale, 2012, 4, 5549-5563.

37 J. Luo, J. Lai, N. Zhang, Y. Liu, R. Liu and X. Liu, ACS Sustainable Chem. Eng., 2016, 4, 1404-1413.

38 Y. Xu, K. Sheng, C. Li and G. Shi, ACS Nano, 2010, 4, 43244330.

39 B. Badhani, N. Sharma and R. Kakkar, $R S C$ Adv., 2015, 5, 27540.

40 L. Zhang, G. Chen, M. N. Hedhili, H. Zhang and P. Wang, Nanoscale, 2012, 4, 7038-7045.

41 W. Chen and L. Yan, Nanoscale, 2011, 3, 3132-3137.

42 Y. Lei, Z. Tang, R. Liao and B. Guo, Green Chem., 2011, 13, 1655-1658.

43 J. Wang, Z. Shi, J. Fan, Y. Ge, J. Yin and G. Hu, J. Mater. Chem., 2012, 22, 22459-22466.
44 H. Gao, Y. Sun, J. Zhou, R. Xu and H. Duan, ACS Appl. Mater. Interfaces, 2013, 5, 425-432.

45 S. W. Hummers and R. E. Offeman, J. Am. Chem. Soc., 1958, 80, 1339.

46 G. Liu, H. Gao, K. Li, J. Xiang, T. Lan and Z. Zhang, J. Colloid Interface Sci., 2018, 514, 338-348.

47 Q. Xia, L. Yang, K. Hu, K. Li, J. Xiang, G. Liu and Y. Wang, ACS Appl. Mater. Interfaces, 2019, 11, 2352-2363.

48 H. Bai, C. Li, X. L. Wang and G. Q. Shi, J. Phys. Chem. C, 2011, 115, 5545-5551.

49 Y. Sun, M. Yang, F. Yu, J. Chen and J. Ma, Prog. Chem., 2015, 27, 1133-1146. 